\title{
Pharmacogenetics of Nicotine Metabolism in Twins: Methods and Procedures
}

\author{
Gary E. Swan', Neal L. Benowitz², Peyton Jacob III2, Christina N. Lessov', Rachel F. Tyndale'3, \\ Kirk Wilhelmsen', Ruth E. Krasnow', Mary R. McElroy', Sharyn E. Moore', and Michelle Wambach' \\ ' Center for Health Sciences, SRI International, California, United States of America \\ ${ }^{2}$ Division of Clinical Pharmacology, Departments of Medicine and Biopharmaceutical Sciences, University of California, San Francisco, \\ United States of America \\ ${ }^{3}$ Department of Pharmacology, University of Toronto, Canada \\ ${ }^{4}$ Department of Genetics, University of North Carolina, United States of America
}

$T_{\text {his }}^{\text {his }}$ his article describes a pharmacogenetic investigation of nicotine metabolism in twins. One hundred and thirty-nine twin pairs (110 monozygotic and 29 dizygotic) were recruited and assessed for smoking status, zygosity, and health conditions known or suspected to affect drug metabolism. Participants underwent a 30-minute infusion of stable isotope-labeled nicotine and its major metabolite, cotinine, followed by an 8-hour in-hospital stay. Blood and urine samples were taken at regular intervals for analysis of nicotine, cotinine, and metabolites by gas chromatography-mass spectrometry or liquid chromatography-mass spectrometry and subsequent characterization of pharmacokinetic phenotypes. DNA was genotyped to confirm zygosity and for variation in the primary gene involved in nicotine metabolism, CYP2A6. Univariate and multivariate biometric analyses planned for the future will determine genetic and environmental influences on each pharmacokinetic measure individually and in combination with each other, and in the presence and absence of covariates, including measured genotype. When the analyses are completed, this study will result in a more complete characterization of the impact of genetic and environmental influences on nicotine and cotinine metabolic pathways than has heretofore been reported. The approach taken, with its use of a quantitative model of nicotine metabolism, highly refined metabolic phenotypes, measured genotype, and advanced tools for biometric genetic analysis, provides a model for the use of twins in next-generation studies of complex drug-metabolism phenotypes.

The use of the twin design to study genetic contributions to variability in human drug response has a history dating back to the early work of Luth (1939; as cited in Weber, 1997) in which the heritability of the plasma half-life of ethanol was estimated from intraclass correlations in 10 pairs of monozygotic (MZ) and 10 pairs of dizygotic (DZ) twins. From the 1950s through the early 1990s, the twin design was used mainly as a strategy to screen for metabolic phenotypes with genetic variation in response to a variety of drugs including the plasma half-life of ethanol (e.g., Vesell et al., 1971), the plasma concentration of lithium (Dorus et al., 1975), and per cent dose of halothane metabolized (an anesthetic; Cascorbi et al., 1971; studies reviewed in Weber, 1997). While these studies typically involved fewer than 20 pairs of twins of each zygosity, the broad heritability estimates of various pharmacokinetic phenotypes ranged from a low of 0.37 (halothane; Cascorbi et al., 1971) to a high of 1.00 (isoniazid; an antibiotic; Bönicke \& Lisboa, 1957, as cited in Weber, 1997). Taken as a whole, the body of evidence from the early twin studies shows substantial genetic involvement in drug metabolism. It is also apparent that the extant literature on pharmacology in twins has examined relatively few pharmacokinetic indices of drug metabolism, has relied on very small samples of twins, and has not used state-of-the-art techniques for quantification of the relative contribution of genetic and environmental influences. Additionally, nicotine metabolic phenotypes have thus far not been investigated in a genetically informative sample.

While nicotine is generally recognized as the single most important compound involved in the processes leading up to and maintaining tobacco dependence (Stolerman \& Jarvis, 1995), the relative contribution of genetic and environmental influences to nicotine metabolic pathways described by Benowitz and Jacob (1997) is unknown. Although certain genes such as P450 CYP2A6 are clearly implicated in relevant pathways for nicotine metabolism (Benowitz, Tyndale et al., 2002; Messina et al., 1997; Nakajima et al., 1996), a complete understanding of all relevant candidate genes (e.g., CYP2B6 [Yamazaki et al., 1999] and

Received 30 April, 2004; accepted 8 July, 2004.

Address for correspondence: Gary E. Swan, Center for Health Sciences, SRI International, 333 Ravenswood Avenue, Menlo Park, CA 94025, USA. E-mail: gary.swan@sri.com 
CYP2D6 [Caporaso et al., 2001; Cholerton et al., 1994]) and their interactions in the pathways has not yet been realized.

A separate, but nonetheless important, issue is the relationship between variation in $\mathrm{P} 450$ genes and nicotine dependence. Polymorphism in CYP2A6, including gene deletion, has been shown in some studies to be associated with the likelihood of being a nonsmoker (Ando et al., 2003; Iwahashi et al., 2004; Pianezza et al., 1998; Sellers et al., 2000; Tyndale \& Sellers, 2001). However, the association has not been confirmed in other studies (Schulz et al., 2001; Zhang et al., 2001). A recent meta-analysis of all studies reported to date concluded that there is not a consistent association between variation in CYP2A6 and smoking behaviors (Carter et al., 2004). Among the possible reasons for inconsistent findings regarding CYP2A6 are, firstly, variation across studies in statistical power, use of ethnically heterogeneous groups, use of different genotyping assays, and different phenotypic definitions (Schoedel et al., 2004), or secondly, that all the genetic variants active in the metabolic pathway are incompletely described, thereby resulting in an increased amount of unaccounted-for variance in the metabolism-dependence association.

There are several reasons why understanding the nature of individual differences in nicotine metabolism is important. Variations in the pharmacokinetics of nicotine could provide clues as to, first, why some people go on to become regular users after initial exposure to tobacco while others experience pronounced adverse reactions and do not initiate regular use (O’Loughlin et al., 2004; Pomerleau et al., 1993); second, why some individuals smoke more heavily than others; and third, why nicotine replacement therapy is more effective in some but not other individuals (Swan \& Carmelli, 1997).

This article describes the convergence of two lines of work that, until now, have evolved independently of each other: (a) biometric genetic studies in twins have demonstrated a significant role for genetic influences on tobacco use and nicotine dependence (Carmelli et al., 1992; Heath \& Madden, 1995; Kendler et al., 1999; Lessov et al., 2004; Li et al., 2003; McGue et al., 2000; Sullivan \& Kendler, 1999; Swan \& Carmelli, 1997; True et al., 1999) and (b) laboratory pharmacology studies have characterized nicotine metabolic pathways (Benowitz \& Jacob, 1997; see Figure 1), documented individual stability over time in nicotine disposition and kinetics, and reported substantial between-subject variability on these parameters (Benowitz \& Jacob, 1994; Benowitz, Perez-Stable et al., 2002; Perez-Stable et al., 1998).

The purpose of the present article is to describe the methodologies used to create and execute the largest twin study of nicotine metabolism (and of any drug) reported to date. We describe methods for recruitment, screening, consenting, genotyping, biological sampling, and calculation of pharmacokinetic parameters. We further describe planned biometric analyses and conclude with a discussion of several challenges and solutions encountered during the course of this investigation.

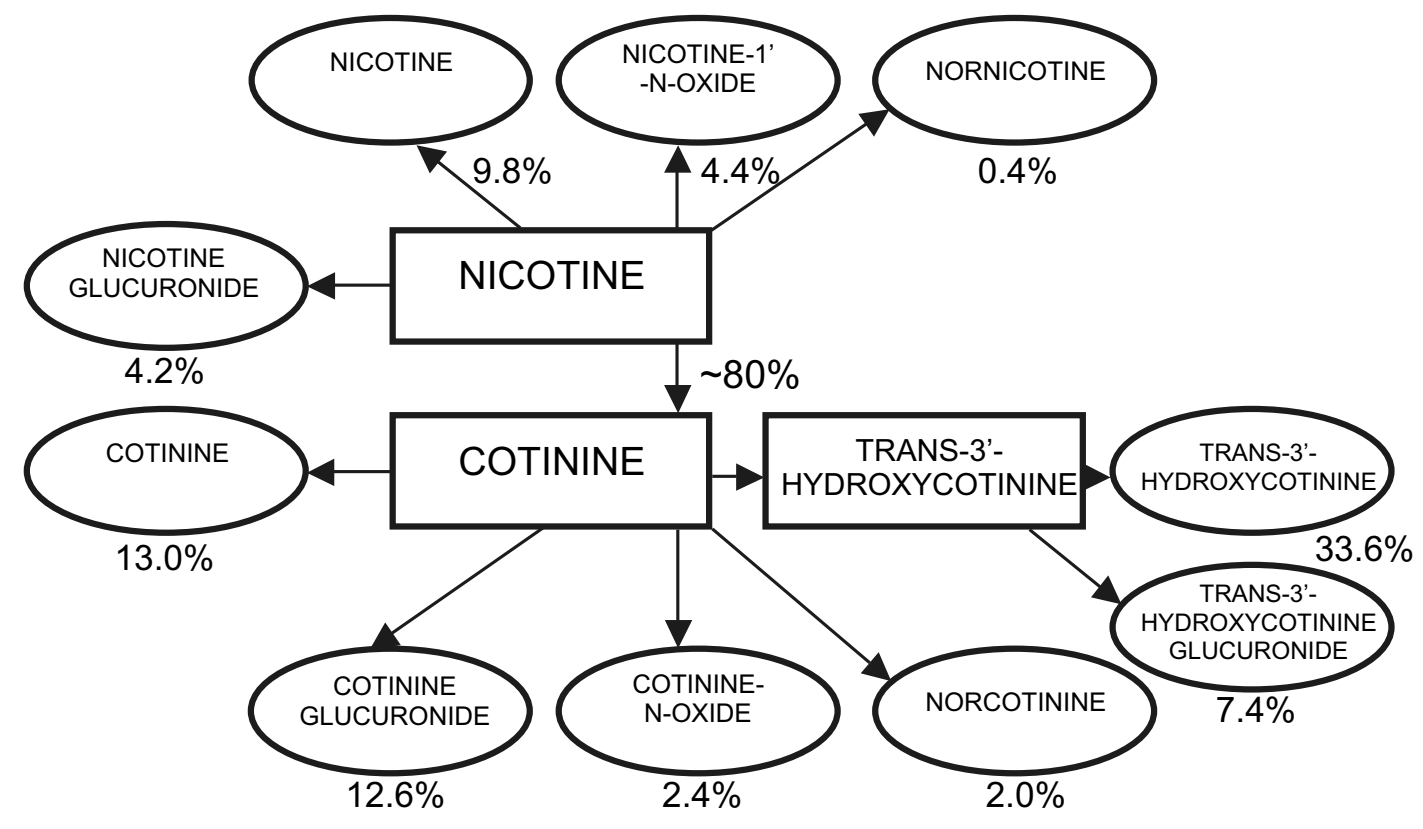

Figure 1

Quantitative scheme of nicotine metabolism.

Modified from Benowitz \& Jacob (1997). Circled compounds are excreted in the urine; numeric values indicate the associated percent of systemic dose of nicotine. 


\section{Methods}

\section{Setting}

The study involved two primary research centers: the Center for Health Sciences at SRI International, California, USA, and the Division of Clinical Pharmacology and Experimental Therapeutics, University of California, San Francisco (UCSF), based at the San Francisco General Hospital Medical Center. SRI was responsible for the recruitment, screening, and scheduling of twin pairs drawn from the SRI Northern California Twin Registry (NCTR; described below) and will be responsible for the planned biometric analyses. UCSF was responsible for conducting the nicotine/cotinine infusion procedure at San Francisco General Hospital (SFGH); for analytical chemistry procedures to determine nicotine, cotinine, and metabolite levels; and for quantification of pharmacokinetic parameters. Additional contributions were made by the University of Toronto, Department of Pharmacology (genotyping for CYP2A6), and by the Department of Neurology, UCSF (molecular determination of zygosity).

\section{Participants}

The NCTR was created in 1995 to fill the need for a pool of twins for genetic studies of drug metabolism. In 1996, an extensive advertising campaign was conducted and included advertising in 19 newspapers, San Francisco Bay area-wide movie theaters, and AM/FM radio stations. Within 2.5 years, this campaign resulted in the enrolment of a total of 1054 twins, a large enough pool from which to recruit twins to the present study. Contact was (and continues to be) maintained with twins in the NCTR via annual newsletters and birthday cards. In addition to the above methods, a 5-year NCTR anniversary-celebration party held in July 2000 increased enrollment to 1765 individual twins. A NCTR website is maintained (http://www.sri.com/policy/twin/) and referrals to the NCTR by registered twins is encouraged. Currently, there are over 2000 twins registered with the NCTR.

\section{Recruitment and Enrollment Procedures Exclusion Criteria}

To minimize the effect of medical conditions and/or medication usage known to influence metabolism, individuals were excluded from participation if they met any of the following criteria:

- age of less than 18 years or more than 65 years

- weight of more than $30 \%$ over ideal height-adjusted weight

- pregnancy

- the presence of any of the following conditions:

- use of drug metabolism-altering medications such as anticonvulsant drugs and barbiturates

— uncontrolled hypertension or diabetes
- a history of heart disease as indicated by selfreport or history of bypass surgery, valve replacement, use of a pacemaker, or angioplasty procedures

- Raynaud's disease

- chronic diseases such as cancer, liver, and kidney diseases, or asthma, that were not stable or were not in remission for at least 1 year

- migraine headaches

- anemia

- abnormal blood-sugar levels that were not well controlled by medication

- substance abuse and/or dependence

- psychiatric disorders that could limit study compliance or require the use of metabolismaltering psychotropic medications

— positive HIV status

- hepatitis B or C

- history of vasovagal reactions

- discomfort with venipuncture procedures, or a self-reported history of 'difficult veins'.

Because the study procedures could be seriously confounded or could lead to adverse events for the participants by the presence of the conditions described above, a three-tiered screening procedure was employed (see below and Figure 2).

All methods for recruitment, informed consent, screening, and data collection were reviewed and approved by the Institutional Review Boards of SRI International and UCSF.

\section{Consent and Recruitment}

At the initial telephone contact, verbal consent was obtained prior to discussion of study details and collection of information relevant to exclusion criteria. Following verbal consent, participants were given a description of study procedures and protocol. To encourage participation, a variety of recruitment incentives were described including the opportunity to receive the results of the DNA-based zygosity analysis; and $\$ 300$ compensation for full participation in the infusion and follow-up procedures. Additionally, because the infusion procedures were designed in such a way as to allow for simultaneous but independent testing of both members of a twin pair, the opportunity to participate with the co-twin over the course of the hospital stay was also described.

\section{Telephone Screen for Exclusionary Conditions}

At the time of first contact and following verbal consent to participate, detailed screening questions were asked to determine eligibility as described above. At this time, participants also provided information required for admission to SFGH. A Phlebotomy Screening Form was completed over the phone to determine preferred time of day and location for future phone contacts and appointments for blood 


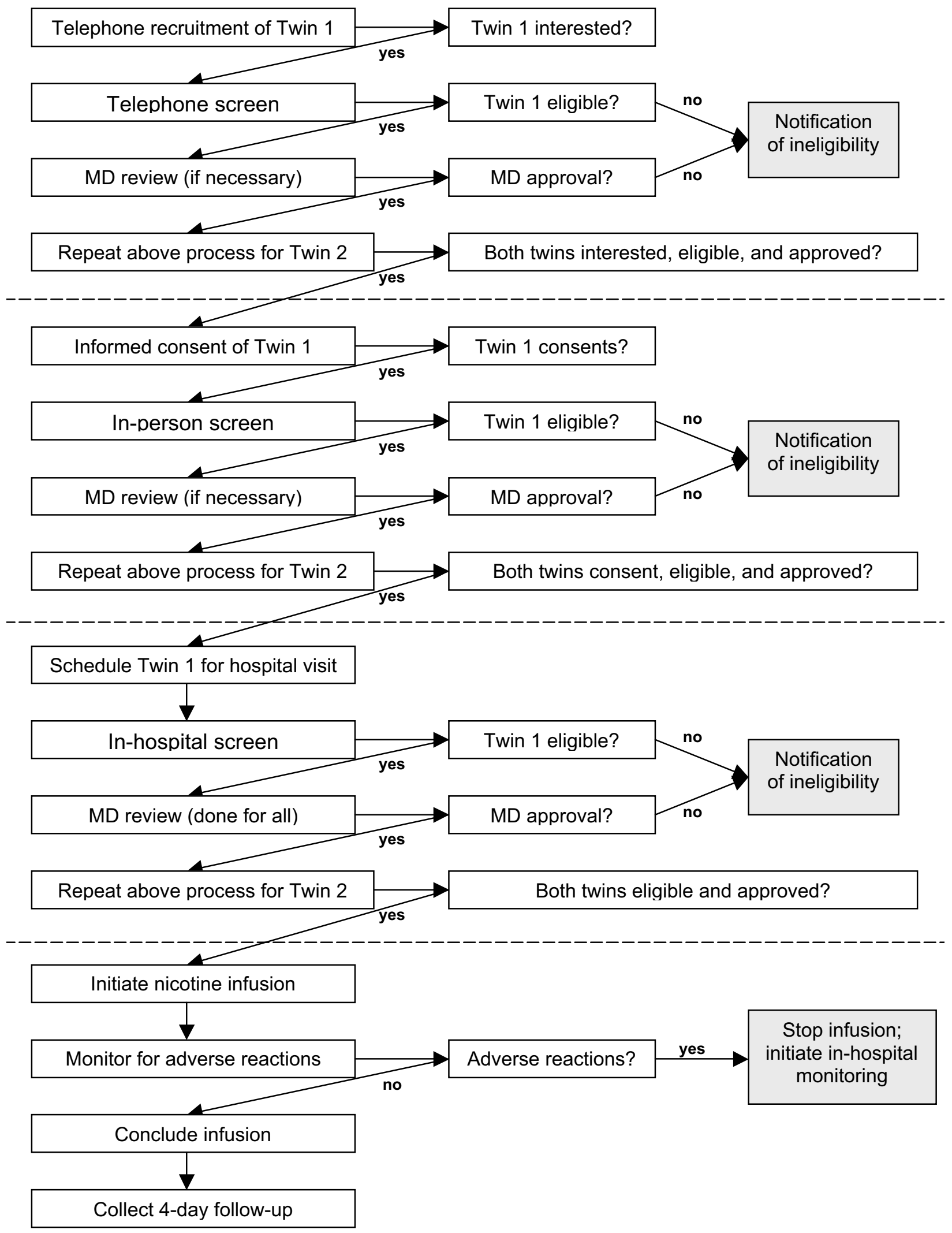

Figure 2

Sequence of activities to recruit, screen, review, consent, schedule, and assess study participants. 
draws, study participation dates, and any relevant information to facilitate future venipuncture procedures. The completed form was sent to the project physician for further review and an indication of exclusion. If both twins met preliminary eligibility following phone screening, an appointment was scheduled with a staff phlebotomist (see below), and a tentative date for the infusion procedure set.

\section{In-Person Screen for Exclusionary Conditions}

Study participants were met at a location of their choice (usually the home or place of employment) by a phlebotomist. Following written consent to participate, detailed information about current medication usage was collected. A minimum of two blood pressure $(\mathrm{BP})$ and heart rate $(\mathrm{HR})$ readings were taken. A $30 \mathrm{ml}$ blood sample was collected for biochemical screening tests along with a urine sample to test for pregnancy in female participants. Participants who did not tolerate venipuncture well (due to a vasovagal reaction, etc.) were advised to reconsider their participation in the study. Laboratory blood tests included complete blood-cell counts; electrolytes; kidney and liver function; hepatitis B and C; and surface antigen, antibody, and nicotine and cotinine concentrations.

Study participants who lived out of state or did not reside in the San Francisco Bay area were directed to a laboratory located near their place of residence to provide blood and urine samples. These results were forwarded to the project manager for review. Subsequent to receipt of study materials, a staff member reviewed details of the consent form with the participant over the telephone and answered any questions about study procedures, risks, and benefits. Participants who were uncertain about their typical $\mathrm{BP}$ and HR readings were asked to have these measured by their own healthcare provider and to report the readings to the project manager.

All participants who gave verbal consent to participate in the study at the initial telephone contact and screen were sent a questionnaire to more completely assess health and smoking history, and use of recreational substances. Participants who met initial screening criteria were asked to bring their questionnaires to the second screening appointment. Those who did not meet criteria were asked to return their completed questionnaires via mail.

All laboratory blood results, BP, and HR readings were subsequently reviewed by the project managers and/or physician. If any laboratory results were not within normal ranges, the participant was contacted by the project physician and referred to another healthcare provider when appropriate. Participants who were deemed eligible after the in-person visit and subsequent review of the clinical data were notified as such. The project recruiter then contacted both members of a twin pair to confirm the previously selected date for the infusion procedure.

\section{In-Hospital Screen for Exclusionary Conditions}

Participants were asked to arrive at SFGH by 7:00 a.m. on the appointed day. They had been asked to abstain from food and, if necessary, cigarette smoking from 10:00 p.m. the night prior to their appointment. Immediately after their arrival, a resting 12-lead ECG and BP and HR measures were obtained. These measurements were again reviewed by the project physician who also conducted a brief physical examination. The clinical research associate then obtained anthropometric measurements to determine body composition (\% fat) and conducted several interviews focusing on family history of smoking, ethno-cultural background, and, for female participants, reproductive information.

\section{Questionnaire Measures}

\section{Zygosity}

Zygosity status was assessed by standard zygosity questionnaire items (Cederlof et al., 1961) and confirmed by DNA genotyping (see below). Zygosity questions included whether, as children, the twins were 'as alike as two peas in a pod'; whether parents, siblings, or teachers had trouble telling them apart; and the twins' own knowledge of their zygosity.

\section{Demographics}

A series of standard questions were asked to determine date of birth, ethnicity, marital status, number of children, and educational attainment.

\section{General Health}

In addition to information pertinent to the previously described exclusionary conditions, participants also provided a history of hospitalization for major medical illness or surgery.

\section{Menstrual Cycle}

The timing of each female participant's menstrual cycle was determined following a previously published approach (Pomerleau et al., 1992). The infusion protocol was scheduled to occur in the midto late-follicular phase (operationally, between the end of the menses and day 11 of the cycle).

\section{Dietary Assessment}

Regular consumption of some substances could possibly influence drug metabolism (Ingelman-Sundberg, 2002). Therefore, a series of questions assessed the frequency and quantity of alcohol consumption, including four questions from the Michigan Alcoholism Screening Test (MAST; Cyr \& Wartman, 1988), and frequency and quantity of caffeinated beverages. Individuals' consumption of foods known to enhance drug metabolism, such as broiled meats and cruciferous vegetables (Conaway et al., 2002; Lampe \& Peterson, 2002; Zhou et al., 2004), was also assessed.

\section{Smoking History}

A series of questions were asked to ascertain smoking status (never, former, or current smoker). Among respondents who reported they were current or 
former regular smokers, data were collected on age of smoking initiation; years smoked; smoking topography, including number of cigarettes smoked and depth of inhalation; and nicotine dependence using the Fagerström Test for Nicotine Dependence (FTND; Heatherton et al., 1991). Potential sources of exposure to environmental tobacco smoke were assessed in all participants.

\section{In-Hospital Pharmacokinetic Study Procedures}

The project physician prepared the nicotine/cotinine solution for all participants who attended SFGH for the infusion appointment. Two factors determined the nicotine dose level: body weight and preinfusion plasma cotinine levels. Participants received 0.5 $\mu \mathrm{g} / \mathrm{kg} / \mathrm{min}$ if plasma cotinine levels were $50 \mathrm{ng} / \mathrm{ml}$ or lower (levels consistent with not smoking or smoking five or fewer cigarettes per day), $1.0 \mu \mathrm{g} / \mathrm{kg} / \mathrm{min}$ if plasma cotinine levels were $50-150 \mathrm{ng} / \mathrm{ml}$ (levels consistent with smoking 5-15 cigarettes per day); and 2.0 $\mu \mathrm{g} / \mathrm{kg} / \mathrm{min}$ if plasma cotinine levels were $>150 \mathrm{ng} / \mathrm{ml}$ (levels consistent with smoking 15 or more cigarettes per day). The dose was always based on the lower plasma cotinine level within a twin pair so that both twins of pairs discordant for smoking received the same dose.

In-dwelling catheters were placed in each arm. The catheter in the right arm was used to deliver the stable isotope-labeled nicotine/cotinine solution while the catheter in the left arm was used to obtain periodic blood samples.

Participants received a simultaneous intravenous infusion of deuterium-labeled nicotine $\left(\right.$ nicotine- $\mathrm{d}_{2}=$ 3', 3'-dideuteronicotine) and cotinine (cotinine- $\mathrm{d}_{4}=2$, 4, 5, 6-tetradeuterocotinine). Labeled compounds are necessary for metabolic studies as individuals who use tobacco already have considerable levels of nicotine and cotinine in their bodies which would make measurement of clearance of unlabeled nicotine or cotinine impossible. The synthesis of these deuteriumlabeled compounds and their preparation for infusion has been described previously (Jacob et al., 1988). During all infusions, participants underwent continuous cardiac monitoring and frequent BP measurements (described below).

Prior to the start of the 30-minute nicotine infusion, baseline blood and urine samples were obtained from each participant. After the start of the infusion, a total of 10 blood samples $(5 \mathrm{ml})$ were obtained at the following intervals: $10,20,30,45,60,90,120$, 180 minutes, and at 4 and 6 hours. All urine was collected over the course of the 8 -hour protocol. In order to make the lengthy 8-hour stay in hospital as pleasant as possible, participants were provided with snacks, meals, a television and a video machine with a large collection of popular movie videos.

Prior to discharge, posthospitalization bloodsample collection procedures and appointment times were reviewed with participants so that blood samples $(5 \mathrm{ml})$ could be obtained on four subsequent consecutive mornings.

Pharmacokinetic Measures. Concentrations of natural and deuterium-labeled nicotine and cotinine in blood were measured by gas chromatography-mass spectrometry (GC-MS) with the use of nicotine $-3^{\prime}, 3^{\prime}-\mathrm{d}_{2}-\mathrm{N}^{\prime}-$ methyl $^{-} \mathrm{d}_{2}\left(\right.$ nicotine $\left.-\mathrm{d}_{4}\right)$ and c o t in in e $-2,4,5,6,4,4^{\prime}-\mathrm{d}_{6}-\mathrm{N}^{\prime}{ }_{-}$ methyl $-\mathrm{d}_{3}\left(\right.$ cotinine $\left.-\mathrm{d}_{9}\right)$ as internal standards $(\mathrm{Jacob}$ et al., 1991). The limit of quantitation was $0.5 \mathrm{ng} / \mathrm{ml}$ for nicotine and cotinine. Concentrations of nicotine $-\mathrm{d}_{2}$ and cotinine $-\mathrm{d}_{4}$ were corrected for the presence of naturally occurring stable isotopes in nicotine from tobacco.

Concentrations of deuterium-labeled nicotine and metabolites in urine were measured using liquid chromatography-tandem mass spectrometry (analyses not yet completed). Each assay measures nicotine, six metabolites, and deuterium-labeled isoptomers (19 analytes in all; Jacob et al., 2002).

Glucuronide-conjugated nicotine, cotinine, and trans-3'-hydroxycotinine were measured as the difference in total concentrations before and after hydrolysis by incubation with beta-glucuronidase, as described previously (Benowitz et al., 1999).

Standard pharmacokinetic parameters were estimated from blood concentration and urinaryexcretion data using model-independent methods described previously (Benowitz \& Jacob, 1994; PerezStable et al., 1998). Total clearances were computed as

$$
\begin{aligned}
\mathrm{CL}_{\text {nic-d }} & =\text { Dose }_{\text {nic-d d }} / \mathrm{AUC}_{\text {nic-d }} \\
\mathrm{CL}_{\text {cot-d }} & =\text { Dose }_{\text {cot-d } d_{4}} / \mathrm{AUC}_{\text {cot-d }}
\end{aligned}
$$

where CL is clearance, AUC is area under the plasmaconcentration curve extrapolated to infinity, nic- $d_{2}$ is labeled dideuteronicotine, and $\cot -d_{4}$ is labeled tetradeuterocotinine.

Renal clearances were calculated as urinary excretion of nicotine or cotinine divided by AUC over 8 hours. Metabolic clearance was estimated as total minus renal clearance.

Fractional conversion of nicotine to cotinine (f) was estimated by using blood levels of cotinine generated from infused nicotine and the clearance of cotinine itself, determined by infusion of cotinine:

$\mathrm{f}=\mathrm{AUC}_{\text {cot-d }} /$ Dose $_{\text {nic-d }} \times \mathrm{CL}_{\text {cot-d }}$

The metabolic clearance of nicotine via the cotinine pathway $\left(\mathrm{CL}_{\text {nic } \rightarrow \text { cot }}\right)$ was computed as $\mathrm{CL}_{\text {nic-d }} \times \mathrm{f}$.

Urine. We measured a number of nicotine metabolites in the urine of the participants. In sum, these metabolites account for an average of $90 \%$ of a dose of nicotine. Nicotine, cotinine, nicotine- $\mathrm{N}$-oxide, cotinine-N-oxide, trans-3'-OH-cotinine (3-HC), and glucuronide conjugates of nicotine, cotinine, and 3-HC are expressed as a percentage of the dose of nicotine administered (Benowitz et al., 1999). 
Pharmacodynamic Measures. BP and HR measures were taken by an automated recording machine 15 times throughout the day in-hospital as follows: one measure immediately prior to the start of the infusion; at 5, 10, 15, 20, 25, and 30 minutes during the infusion; and at 45, 60, 90, 120, and 180 minutes and 4,6 , and 8 hours after the infusion. Cardiac monitoring was performed continuously throughout the period of infusion and for an additional 30 minutes postinfusion.

\section{Genotyping for Zygosity}

Self-reported zygosity was confirmed by genotyping highly polymorphic microsatellite markers on 11 chromosomes (D1S1612, D2S1788, D3S1764, D4S2368, D5S1501, D7S513, D8S1110, D13S1796, D14S608, D16S753 and D15S657) using the method described by Weber and May (1989).

\section{Genotyping for CYP2A6}

Genotyping of CYP $2 A 6 * 1 \times 2$, CYP $2 A 6 * 2$, $C Y P 2 A 6 * 4$, and CYP $2 A 6 * 7$ was performed according to previously described protocols (Goodz \& Tyndale, 2002; Rao et al., 2000; Xu, Rao et al., 2002). Methods to detect CYP $2 A 6 * 9$ and CYP $2 A 6 * 12$ alleles are described elsewhere (Schoedel et al., 2004). Each allelic assay relies on a two-step polymerase chain reaction (PCR)-detection system, where the first amplification uses genomic DNA as the template with gene-specific primers and the second amplification uses DNA derived from the first PCR amplification with allele-specific primers. Taq polymerase was obtained from Gibco BRL (Life Technologies, Burlington, Canada) or MBI Fermentas (Burlington, Canada). For the genotyping procedures, each set of samples included three positive controls with the different genotyping combinations and a negative control lacking DNA. All PCR amplifications were performed using PTC-200 Peltier Thermal Cyclers, and the second amplification products were analyzed on $1.2 \%$ or $3 \%$ agarose gels (OnBio, Richmond Hill, Canada) containing ethidium bromide. A $1 \mathrm{~kb}$ DNA ladder was used for each set of samples to confirm the appropriate amplicon sizes. Genotyping for variation in CYP2B6 and CYP2D6 is underway and results will be reported at a later date.

\section{Participant Process Measures}

In order to assess any concerns or questions that participants may have had during and following their participation in the study, specific information on participant reactions to all phases of the study was obtained. For all phases of the study, participants were asked for their suggestions for improving procedures, whether they would recommend the study to other twins, and whether they would participate in future NCTR studies.

\section{$\overline{\text { Results }}$}

A pool of 1054 twins from which to recruit for this study was available. The nicotine infusion and biolog- ical-sample collection protocol was completed successfully in $278(88.5 \%)$ of the 314 twins scheduled. There were both medical and nonmedical reasons for nonparticipation and failure to complete the entire study (Figure 3). One hundred and ninety-two twins $(18.2 \%)$ refused participation for a variety of reasons, including 'fear of blood draws or needles' ( $n=23$; $12 \%)$, 'too busy' $(n=56 ; 29 \%)$, 'concern about effects of nicotine' ( $n=33 ; 17 \%)$, or 'other' $(n=80$; $42 \%)$. At the initial telephone screen, 542 twins ( $51 \%$ of the total contacted) were deemed to be ineligible for participation due to the presence of one of the following conditions: health $(n=266 ; 49 \%)$, being overweight $(n=125 ; 23 \%)$, ineligibility of the co-twin $(n=114 ; 21 \%)$, or psychiatric condition $(n=38 ; 7 \%)$. At the in-person screen, an additional 6 twins were deemed to be ineligible due to blood chemistry results (hepatitis; $n=3 ; 50 \%$ ) or negative reactions to venipuncture $(n=3 ; 50 \%)$. At the in-hospital appointment, 20 more twins were determined to be ineligible due to a history of severe vasovagal reactions $(n=10 ; 50 \%)$, abnormal ECG $(n$ $=6 ; 30 \%)$, elevated $\mathrm{BP}(n=2 ; 10 \%)$, or negative reaction to the infusion $(n=2 ; 10 \%)$. In all, 561 $(53.3 \%)$ twins were determined to be ineligible for participation in this investigation. Sixteen twins (5.1\% of the 314 twins scheduled) failed to arrive for their in-hospital appointment.

\section{Characteristics of Eligible and Ineligible Twins}

Table 1 compares demographic, health, and smoking characteristics between infusion-protocol ineligible $(n$ $=548)$ and eligible twins $(n=314)$. These groups were similar with respect to zygosity, sex, educational attainment, smoking status, use of alcohol, use of prescription medications, and fainting history. Relative to ineligible twins, eligible volunteers were younger (36.1 vs. 40.8 years; $p<.01$ ), more likely to be married or living with someone $(54.4 \%$ vs. $45.8 \%$; $p$ $<.05)$, and were more ethnically diverse $(21.7 \%$ vs. $15.6 \%$ nonwhite; $p<.05)$. Among nonwhite study participants, $14.7 \%$ were African American, $52.9 \%$ were Hispanic, $20.6 \%$ were Asian, and $11.8 \%$ were 'other'. Given the extensive exclusion criteria, relative to those who were eligible, ineligible twins were more likely to be greater than $30 \%$ overweight $(14.6 \%$ vs. $0.6 \%, p<.01)$ and have higher rates of hypertension $(12.3 \%$ vs. $2.6 \% ; p<.01)$, heart disease $(5.7 \%$ vs. $0.3 \% ; p<.01)$, diabetes $(4.0 \%$ vs. $1.3 \% ; p<.05)$, and psychiatric conditions $(12.8 \%$ vs. $5.8 \% ; p<.01)$.

\section{Pharmacokinetic Parameters in Study Sample}

Complete data for pharmacokinetic phenotypes were ultimately available from a total of 138 complete twin pairs. For one twin of an additional MZ male-male pair (total $n=139$ twin pairs), nicotine clearance data were not available due to technical problems. The sample, by zygosity, comprised $75 \mathrm{MZ}$ female and 34 MZ male same-sex twin pairs; $19 \mathrm{DZ}$ female and 4 
Table 1

Comparison of Ineligible with Eligible Study Participants

\begin{tabular}{|c|c|c|}
\hline Characteristics & $\begin{array}{l}\text { Ineligible } \\
n=548\end{array}$ & $\begin{array}{l}\text { Eligible } \\
n=314\end{array}$ \\
\hline Age, mean (SD) & $40.8(13.8)$ & $36.1(12.0)^{* *}$ \\
\hline Zygosity (self-reported), \% DZ & 29.7 & 29.0 \\
\hline Gender, \% female & 72.2 & 70.4 \\
\hline Education, \% > high school & 73.6 & 78.2 \\
\hline $\begin{array}{l}\text { Marital status, } \% \text { married or } \\
\text { cohabiting }\end{array}$ & 45.8 & $54.4^{*}$ \\
\hline Ethnicity, \% nonwhite & 15.6 & $21.7^{*}$ \\
\hline $\begin{array}{l}\text { Smoking status, } \% \\
\text { ever smoke } \\
\text { currently smoke }\end{array}$ & $\begin{array}{l}44.3 \\
18.6\end{array}$ & $\begin{array}{l}39.0 \\
16.6\end{array}$ \\
\hline$>30 \%$ overweight, $\%{ }^{a}$ & 14.6 & $0.6^{* *}$ \\
\hline Screening Questionnaire & $n=228^{b}$ & $n=314$ \\
\hline Drink alcohol, \% yes & 72.8 & 79.9 \\
\hline Prescription meds, $\%$ yes & 55.9 & 48.2 \\
\hline Hypertension history, \% yes & 12.3 & $2.6^{* *}$ \\
\hline $\begin{array}{l}\text { Coronary heart disease history, } \\
\% \text { yes }\end{array}$ & 5.7 & $0.3^{* *}$ \\
\hline Diabetes history, \% yes & 4.0 & $1.3^{*}$ \\
\hline Other illness, $\%$ yes & 19.9 & $9.3^{* *}$ \\
\hline Psychiatric disorder, \% yes & 12.8 & $5.8^{* *}$ \\
\hline Ever fainted, $\%$ yes & 33.3 & 33.1 \\
\hline
\end{tabular}

DZ male same-sex twin pairs; and 6 DZ female-male twin pairs.

Table 2 shows the means of eight weight-adjusted $\mathrm{CL}$, volume of distribution $\left(\mathrm{V}_{s s}\right)$ parameters, as well as nicotine and cotinine half-life $\left(\mathrm{t}^{1} / 2\right)$ measures, separately for $\mathrm{MZ}$ and $\mathrm{DZ}$ twins. Means were compared across zygosity groups, adjusting for nonindependence of data in twin pairs, as well as for age, sex,
Table 2

Pharmacokinetic Parameters (Means $\pm S D$ ) in $\mathrm{MZ}$ and DZ Zygosity Groups

\begin{tabular}{|c|c|c|}
\hline Pharmacokinetic measures & $\begin{array}{c}\text { MZ twin pairs } \\
\quad(n=110)\end{array}$ & $\begin{array}{c}\text { DZ twin pairs } \\
\quad(n=29)\end{array}$ \\
\hline $\mathrm{CL}_{\text {nic-d }{ }^{\prime}}, \mathrm{mL} / \mathrm{min} / \mathrm{kg}$ & $18.0 \pm 6.2$ & $17.8 \pm 6.2$ \\
\hline $\mathrm{V}_{s s}$ nicotine, $\mathrm{L} / \mathrm{kg}$ & $2.5 \pm 0.7$ & $2.4 \pm 0.6$ \\
\hline$t^{1} / 2$ nicotine, $\min$ & $119 \pm 41$ & $113 \pm 34$ \\
\hline f & $0.75 \pm 0.13$ & $0.77 \pm 0.14$ \\
\hline $\mathrm{CL}_{\text {nic } \rightarrow c o t}, \mathrm{~mL} / \mathrm{min} / \mathrm{kg}$ & $13.7 \pm 5.9$ & $14.0 \pm 6.2$ \\
\hline $\mathrm{CL}_{\text {cot- } \mathrm{d}_{4}}, \mathrm{~mL} / \mathrm{min} / \mathrm{kg}$ & $0.72 \pm 0.36$ & $0.74 \pm 0.36$ \\
\hline $\mathrm{V}_{s s}$ cotinine, $\mathrm{L} / \mathrm{kg}$ & $1.0 \pm 0.3$ & $1.0 \pm 0.3$ \\
\hline$t 12 / 2$ cotinine, $\min$ & $1080 \pm 348$ & $1045 \pm 363$ \\
\hline
\end{tabular}

current smoking, and use of medications, where appropriate (StataCorp, 2001). MZ and DZ twins did not significantly differ in mean metabolic parameters.

In advance of planned multivariate biometric analyses, Table 3 shows MZ and DZ twin-pair Pearson correlation coefficients between metabolic measures. In MZ twins, overall, metabolic measures in one twin significantly correlated with metabolic measures in the cotwin, suggesting that covariation in metabolic phenotypes may be, in part, due to familial (genes plus shared environment) factors. In contrast, in DZ twins, most cross-twin cross-phenotype correlations were not significant. Significant correlations in MZ but not in DZ twins suggests that covariation among metabolic parameters may be largely due to genes rather than to shared environmental factors.

\section{CYP2A6 Genotype Frequencies}

In a subset of twins, each of whom was randomly selected from a pair with genotypic data, the following allele frequencies were observed: wild-type alleles

\section{Table 3}

Cross-Twin Cross-Phenotype Correlations for Pharmacokinetic Parameters in MZ Twins ( $n=110$ pairs; above the diagonal) and DZ Twins ( $n=29$ pairs; below the diagonal)

\begin{tabular}{|c|c|c|c|c|c|c|c|c|}
\hline \multirow[t]{2}{*}{ Twin 2} & \multicolumn{8}{|c|}{ Twin 1} \\
\hline & $\mathrm{CL}_{\text {nic-d }}$ & $\mathrm{V}_{s s \text { nic }}$ & $\mathrm{t}^{1} / 2$ nic & $f$ & $\mathrm{CL}_{\text {nic } \rightarrow c o t}$ & $\mathrm{CL}_{\text {cot-d }}$ & $\mathrm{V}_{s s \cot }$ & $\mathrm{t}^{1} / 2 \cot$ \\
\hline $\mathrm{CL}_{n i c-d_{2}}$ & - & $.33^{* *}$ & $-.45^{* *}$ & $.21^{* *}$ & $.61^{* *}$ & $.41^{* *}$ & $.33^{* *}$ & $-.36^{* *}$ \\
\hline $\mathrm{V}_{s s \text { nic }}$ & .14 & - & .07 & .01 & $.25^{* *}$ & .09 & $.17^{*}$ & -.06 \\
\hline$t^{1} / 2$ & -.11 & .22 & - & $-.26^{* *}$ & $-.44^{* *}$ & $-.35^{* *}$ & $-.21^{* *}$ & $.36^{* *}$ \\
\hline f & .12 & .09 & -.03 & - & $.39^{* *}$ & .06 & .04 & $-.23^{* *}$ \\
\hline $\mathrm{CL}_{n i c \rightarrow c o t}$ & .16 & .12 & -.08 & .13 & - & $.34^{* *}$ & $.30^{* *}$ & $-.35^{* *}$ \\
\hline $\mathrm{CL}_{\text {cot-d }}$ & -.11 & -.15 & -.05 & .11 & -.07 & - & $.32^{* *}$ & $-.35^{* *}$ \\
\hline $\mathrm{V}_{s s \cot }$ & -.13 & -.23 & -.10 & .06 & -.10 & -.16 & - & .03 \\
\hline $\mathrm{t}^{1} / 2_{\cot }$ & -.02 & -.09 & -.11 & -.06 & .01 & -.07 & $.48^{* *}$ & - \\
\hline
\end{tabular}




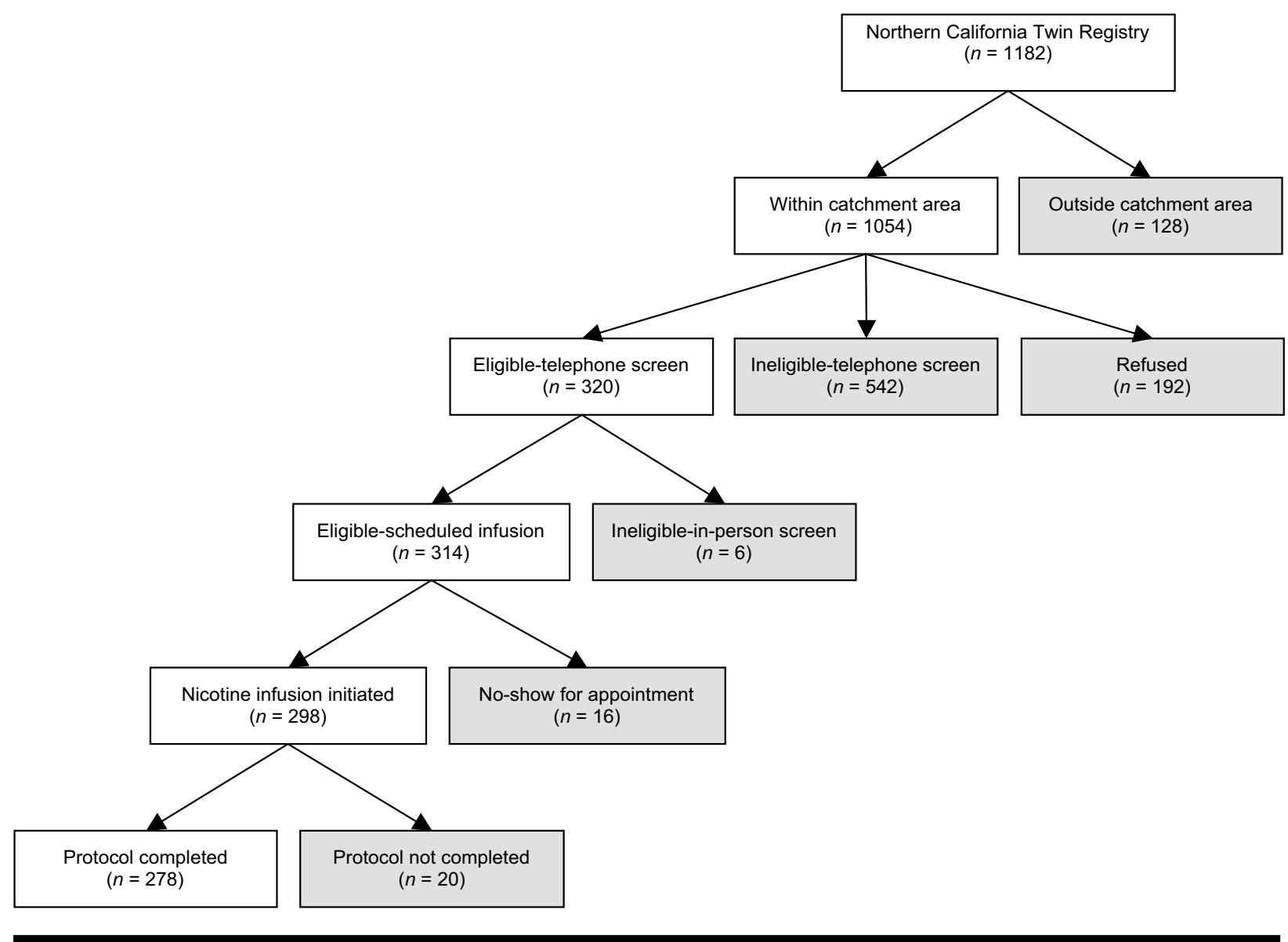

Figure 3

Recruitment, eligibility, and examination experience.

(including $* 1 A$ and $* 1 B ; n=231,84.31 \%$ ), $* 1 \times 2$ alleles $(n=5,1.82 \%), * 2$ alleles $(n=6,2.19 \%), * 4$ alleles $(n=7,2.55 \%), * 9$ alleles $(n=17,6.20 \%), * 12$ alleles $(n=8,2.92 \%)$. These frequencies are similar to those reported previously for a sample of unrelated individuals of European descent (Schoedel et al., 2004).

\section{Participant Process Responses}

During the course of the study, 124 participants provided feedback concerning their experiences with study activities via telephone interviews. Sixteen per cent of the participants reported unusual or unexpected discomfort caused by the blood draws during the screening phase and $14 \%$ reported discomfort during the 4-day follow-up, largely attributable to residual soreness related to the use of in-dwelling catheters in both arms during the previous in-hospital infusion. When asked if they would recommend the study to other twins, 97\% said 'Yes'. Ninety-nine per cent said they would be willing to participate in future NCTR studies.

\section{$\overline{\text { Discussion }}$}

Execution of the methods described in this article led to the creation of the largest study of drug metabo- lism in twins reported to date. The method of recruitment, screening, in-hospital and follow-up assessment resulted in the collection of state-of-the-art metabolic phenotypes that will be, in turn, subjected to biometric genetic analysis to estimate the relative contribution of genetic and environmental factors in univariate and multivariate models. One objective is to determine the range of magnitude of heritability estimates on individual metabolic phenotypes. Another objective is to estimate the extent to which the same genetic factors account for covariation among the various metabolic measures. This will be important information for the eventual mapping of the genetic architecture of these complex traits. The presence of both males and females affords the opportunity to determine the extent to which sex is an important contributor to the observed cross-twin and cross-phenotype covariances. Finally, the fact that all participants were genotyped for variation in CYP2A6 (and are being genotyped for CYP2D6 and CYP2B6) will make it possible to incorporate genotype into the biometric models of metabolism, an approach intended to take full advantage of the unique dataset acquired over the course of this investigation (van den Oord et al., 2004; van den Oord \& Sneider, 2002). 


\section{Generalizability of the Study Sample}

The characteristics of the NCTR and participant samples were similar with regard to gender and zygosity. However, most likely as a result of the method of recruitment for the NCTR, both samples had an overrepresentation of females and MZ twins. This situation is similar to other twin studies which have relied on recruitment through the media, and largely reflects a bias in the nature of volunteers for research (Lykken et al., 1987).

The overall rate of nonwhite participation in this study is below the 2000 United States Census estimate (http://factfinder.census.gov) for nonwhites residing in the San Francisco Bay area $(41.3 \%)$, and increasing participation among nonwhites in research studies, in general, remains a serious issue (Britton et al., 1999; Seto, 2001). The rate of current smoking in study participants $(16.6 \%)$ is lower than the national median prevalence $(23.1 \%$; Centers for Disease Control, 2004) and most likely reflects the effects of the California tobacco-control campaign, one of the most aggressive smoking-reduction programs in the United States (Pierce et al., 1998). On the other hand, the percentage of participants reporting consumption of alcohol $(79.9 \%)$ is somewhat higher than that reported for the California population $(65.1 \%$; Centers for Disease Control, 2000).

Pharmacokinetic parameter means in $\mathrm{MZ}$ and $\mathrm{DZ}$ twins are comparable to those published in previous studies using the same methodology for computing metabolic parameters but different samples of women and men of European descent (Benowitz, Perez-Stable et al., 2002; Perez-Stable et al., 1998). Consistency across studies validates the measurement of nicotine metabolic phenotypes, which may represent more biologically relevant phenotypes to understanding tobacco use and nicotine dependence (Swan et al., 2003).

\section{Planned Biometric Analyses}

Genetic analysis will be conducted in univariate context in which variance in a single phenotype will be examined, or in multivariate context in which the covariance among two or more metabolic phenotypes will be examined. In the univariate approach, we will determine the heritability of all nicotine pharmacokinetic parameters, numerous smoking measures, as well as HR and BP and their change over the course of the nicotine infusion protocol. We will also investigate whether pharmacokinetic parameters are under the combined influence of the same, overlapping, or distinct genetic and environmental factors. This latter approach will be especially important in gaining a better understanding of the heterogeneity of factors that influence nicotine metabolic phenotypes. Finally, all biometric models will be examined for goodnessof-fit in the absence and presence of covariates such as age, gender, BMI, and CYP2A6 genotype. With the completion of genotyping of the remaining two P450 genes, indicator variables for the three genotypes and their interactions will be included in advanced biometric models to determine whether this additional information further increases goodness-of-fit.

\section{Study Limitations}

Limited Number of DZ Twin Pairs. The number of DZ twin pairs recruited to this study was lower than anticipated. Nonetheless, given our sample size, and assuming no significant contribution from shared environmental sources, we will have more than $80 \%$ power to detect genetic effects of $30 \%$ or greater in univariate analysis of the continuous pharmacokinetic phenotypes. In preliminary univariate genetic analyses in a subset of twins, we found evidence for substantial heritability $(66.3 \%)$ of the weight-adjusted nicotine clearance parameter (Swan et al., 2001). We will have sufficient power for bivariate genetic analysis (i.e., estimating the genetic correlation between pairs of metabolic phenotypes, or between metabolic and cigarette-smoking phenotypes). Specifically, we will be able to detect a genetic correlation of .5 as long as each of the two measured phenotypes have heritability estimates of $35 \%$ or greater. We will, however, be underpowered for modeling sex effects.

\section{Lack of Ethnic Variation}

The results from this investigation will be generalizable to individuals of European descent. There are reasons to believe that the relative frequencies of inactive variants responsible for nicotine metabolism may well be different in individuals of other ethnicities. For example, individuals of Chinese descent are known to have a higher prevalence of CYP2A6 variants associated with slower nicotine metabolism (Oscarson et al., 1999, 2002; Xu, Goodz et al., 2002), and this is reflected in lower levels of measured total and nonrenal CL of nicotine and cotinine and $\mathrm{CL}_{\text {nic } \rightarrow \text { cot }}$, as well as in lower rates of daily number of cigarettes smoked (Benowitz, Perez-Stable et al., 2002). Variation among racial groups also exists in other nicotine metabolic pathways such as nicotine and cotinine glucuronidation (Benowitz et al., 1999). This suggests that additional differences in the rates of nicotine metabolism among racial groups may be due to variation in the frequencies of allelic variants in genes responsible for nicotine-N-1-oxidation (i.e., flavin containing monooxygenase 3 gene; Cashman et al., 1995) and glucuronidation (i.e., UDP-glucuronyltransferase genes; de Leon, 2003; Nakajima et al., 2002). For these reasons, we plan to pursue a twin study of nicotine metabolism in other racial populations in the near future (e.g., Yang et al., 2002).

\section{Complexity of the In-hospital Infusion Protocol}

Most detailed studies of nicotine metabolism in the past have relied on the intravenous administration of nicotine with multiple blood and urine samples for measurement of nicotine and metabolites. The complexity of the exclusion criteria and subsequent logistical requirements resulted in far fewer eligible 
twin volunteers than we might otherwise have had for this study. In order to reduce complexity and enhance participant acceptance of metabolic investigations, we recently developed a novel way to study nicotine metabolism using the oral administration of small doses of deuterium-labeled nicotine and cotinine, with measurement of blood, saliva, and urine concentrations of nicotine and metabolites (Dempsey et al., in press). We have utilized this new approach in a small sample of twins and have found acceptance to be much higher, especially for individuals of nonEuropean descent.

\section{The Potential Impact of Violations} of the Equal Environment Assumption

The twin method relies on the assumption that traitrelevant environmental influences contribute equally to the resemblance of $\mathrm{MZ}$ and $\mathrm{DZ}$ twin pairs (Pam et al., 1996). Environmental influences that are more similar for $\mathrm{MZ}$ compared to $\mathrm{DZ}$ twin pairs may be associated with a metabolic phenotype and could account for greater similarity between $\mathrm{MZ}$ than DZ twins (i.e., inappropriately inflating estimates of heritability). One way to address possible violations in the equal environment assumption is to test whether $M Z$ and DZ twins differ in aspects that may affect nicotine metabolism (e.g., diet) and test whether such differences are associated with differences in MZ compared to DZ twin-pair similarity on nicotinemetabolism measures.

\section{Conclusions}

A number of unanticipated challenges were encountered throughout this study that were largely a function of the complexity of the exclusion criteria and the inherent difficulty associated with processing related individuals through concurrent procedural steps. Both members of a twin pair were required to agree to participate and to meet eligibility requirements. Therefore, recruitment efforts failed with some twin pairs due to inability to reach consensus regarding participation or the ineligibility of one of the co-twins.

Participants were further required to be available to meet with a staff phlebotomist by 1 p.m. on the following 4 consecutive days in order to obtain postinfusion blood samples. The rate of successful collection of these samples was enhanced when these samples were obtained at a time and place that was convenient for participants. In order to anticipate participant travel during the 4-day postinfusion interval, blood tubes and shipping supplies were provided at the time of the infusion. Arrangements were then made for traveling participants to provide blood samples at laboratory facilities convenient to their destination, as necessary.

The twins themselves played a key role in the success of this study through their exceptional interest and commitment to the study. Despite their busy schedules $(85 \%$ were in the work force and $46 \%$ had young children), twins agreed to devote a minimum of 16 hours to study appointments along with the time involved in numerous recruitment, screening, and appointment-setting and appointment-confirmation telephone calls. By doing so they have made a critical contribution to the largest-ever twin study of drug metabolism. Subsequent analyses of this important resource will shed further light on genetic and environmental variation in nicotine metabolism in its entire complexity.

\section{Acknowledgments}

This research was supported by the National Institute on Drug Abuse grants DA11170 (GES), DA02277 (NLB), and DA12393 (NLB). It was carried out in part at the General Clinical Research Center at San Francisco General Hospital Medical Center with support of the NIH Division of Research Resources, grant RR00083, and at the University of Toronto with support of grant CIHR MOP 53248 (RFT) and a CRC to RFT.

The authors wish to thank the following people for their work on this study (listed alphabetically): Faith Allen, MD (data manager); Dorit Carmelli, PhD (consultant); Delia Dempsey, MD (project physician); Brenda Herrera (clinical research associate); Lori Karan, MD (project physician); Gunnard Modin (pharmacokinetic analysis); Ovide Pomerleau, PhD (consultant); Huijun Ring, PhD (consultant); Jill Rubin (recruiter); Kerri Schoedel (molecular biologist); Sylvia Wu (chemist); Bo Xu, MD (molecular biologist); and Lisa Yu (chemist).

We are deeply grateful to the twins for their participation. Without them this work would not have been possible.

\section{References}

Ando, M., Hamajima, N., Ariyoshi, N., Kamataki, T., Matsuo, K., \& Ohno. Y. (2003). Association of CYP2A6 gene deletion with cigarette smoking status in Japanese adults. Journal of Epidemiology, 13, 176-181.

Benowitz, N. L., \& Jacob, P., III. (1994). Metabolism of nicotine to cotinine studied by a dual stable isotope method. Clinical Pharmacology and Therapeutics, 56, 483-493.

Benowitz, N. L., \& Jacob, P., III. (1997). Individual differences in nicotine kinetics and metabolism in man. In R. S. Rapaka, N. Chiang, \& B. R. Martin (Eds.), Pharmacokinetics, metabolism, and pharmaceutics of drugs of abuse (pp. 48-64). United States Department of Health and Human Services: National Institute on Drug Abuse.

Benowitz, N. L., Perez-Stable, E. J., Fong, I., Modin, G., Herrera, B., \& Jacob, P., III. (1999). Ethnic differences in $\mathrm{N}$-glucuronidation of nicotine and cotinine. Journal of Pharmacology and Experimental Therapeutics, 291, 1196-1203. 
Benowitz, N. L., Perez-Stable, E. J., Herrera, B., \& Jacob, P., III. (2002). Slower metabolism and reduced intake of nicotine from cigarette smoking in ChineseAmericans. Journal of the National Cancer Institute, 94, 108-115.

Benowitz, N. L., Tyndale, R., Jacob, P., III, \& Swan, G. (2002). CYP2A6 polymorphism and nicotine metabolism [Abstract]. Clinical Pharmacology and Therapeutics, 71, 41.

Britton, A., McKee, M., Black, N., McPherson, K., Sanderson, C., \& Bain, C. (1999). Threats to applicability of randomized trials: Exclusions and selective participation. Journal of Health Services Research and Policy, 4, 112-121.

Caporaso, N. E., Lerman, C., Audrain, J., Boyd, N. R., Main, D., Issaq, H. J., Utermahlan, B., Falk, R. T., \& Shields, P. (2001). Nicotine metabolism and CYP2D6 phenotype in smokers. Cancer Epidemiology Biomarkers and Prevention,10, 261-263.

Carmelli, D., Swan, G. E., Robinette, D., \& Fabsitz, R. R. (1992). Genetic influence on smoking: A study of male twins. New England Journal of Medicine, 327, 829-833.

Carter, B. L., Long, T. Y., \& Cinciripini, P. (2004). A meta-analytic review of the CYP2A6 genotype and smoking behavior. Nicotine \& Tobacco Research, 6, 221-227.

Cascorbi, H. F., Vesell, E. S., Blake, D. A., \& Helrich, M. (1971). Genetic and environmental influence on halothane in twins. Clinical Pharmacology and Therapeutics, 12, 50-55.

Cashman, J. R., Park, S. B., Berkman, C. E., \& Cashman, L. E. (1995). Role of hepatic flavin-containing monooxygenase 3 in drug and chemical metabolism in adult humans. Chemical and Biological Interactions, 96, 33-46.

Cederlof, R., Friberg, L., Jonsson, E., \& Kaij, L. (1961). Studies on similarity diagnosis in twins with the aid of mailed questionnaires. Acta Geneticae Medicae et Gemellologiae (Roma), 11, 338-362.

Centers for Disease Control. (2000, March 24). Statespecific prevalence of selected health behaviors, by race and ethnicity - Behavioral Risk Factor Surveillance System, 1997. Morbidity and Mortality Weekly, 49, No. SS-2.

Centers for Disease Control. (2004, January 9). State-specific prevalence of current cigartette smoking among adults - United States, 2002. Morbidity and Mortality Weekly, 52, No. 53.

Cholerton, S., Arpanahi, A., McCracken, N., Boustead, C., Taber, H., Johnstone, E., Leathart, J., Daly, A. K., \& Idle, J. R. (1994). Poor metabolisers of nicotine and CYP2D 6 polymorphism. Lancet, 343, 62-63.

Conaway, C. C., Yang, Y. M., \& Chung, F. L. (2002). Isothiocyanates as cancer chemopreventive agents: Their biological activities and metabolism in rodents and humans. Current Drug Metabolism, 3, 233-255.
Cyr, M. G., \& Wartman, S. A. (1988). The effectiveness of routine screening questions in the detection of alcoholism. Journal of the American Medical Association, 259, 51-54.

de Leon, J. (2003). Glucuronidation enzymes, genes and psychiatry. International Journal of Neuropsychopharmacology, 6, 57-72.

Dempsey, D., Tutka, P., Jacob, P., III, Allen, F., Schoedel, K., Tyndale, R. F., \& Benowitz, N. L. (in press). Nicotine metabolite ratio as an index of CYP2A6 metabolic activity. Clinical Pharmacology and Therapeutics.

Dorus, E., Pandey, G. N., \& Davis, J. M. (1975). Genetic determinants of lithium ion distribution. Archives of General Psychiatry, 32, 1097-1102.

Goodz, S. D., \& Tyndale, R. F. (2002). Genotyping human CYP2A6 variants. In E. F. Johnson \& M. R. Waterman (Eds.), Methods in enzymology (pp. 59-69). New York: Academic Press.

Heath, A. C., \& Madden, P. A. F. (1995). Genetic influences on smoking behavior. In R. J. Turner, L. R. Cardon, \& J. D. Hewitt (Eds.), Behavior genetic approaches in behavioral medicine (pp. 45-56). New York: Plenum Press.

Heatherton, T. F., Kozlowski, L. T., Frecker, R. C., \& Fagerström, K. O. (1991). The Fagerström Test for Nicotine Dependence: A revision of the Fagerström Tolerance Questionnaire. British Journal of Addiction, 86, 1119-1127.

Ingelman-Sundberg, M. (2002). Polymorphism of cytochrome $\mathrm{P} 450$ and xenobiotic toxicity. Toxicology, 181-182, 447-52.

Iwahashi, K., Waga, C., \& Takimoto, T. (2004). Whole deletion of the CPY2A6 gene (CYP2A6 AST;4C) and smoking behavior. Neuropsychobiology, 49, 101-104.

Jacob, P., III, Benowitz, N. L., \& Shulgin, A. T. (1988). Synthesis of optically pure deuterium-labeled nicotine, nornicotine and cotinine. Journal of Labeled Compounds and Radiopharmaceuticals, 25, 1117-1128.

Jacob, P., III, Yu, L., \& Benowitz, N. L. (2002, October). Determination of nicotine, its major metabolites, and deuterium-labeled isoptomers in human urine using LC-MS/MS. Paper presented at the Eleventh North American meeting of the International Society for the Study of Xenobiotics, Orlando, FL. Abstract published in Drug Metabolism Reviews, 34(Suppl. 1), 160.

Jacob, P., III, Yu, L., Wilson, M., \& Benowitz, N. L. (1991). Selected ion monitoring method for determination of nicotine, cotinine, and deuterium-labeled analogs. Absence of an isotope effect in the clearance of (S)-nicotine-3'-3'- $\mathrm{d}_{2}$ in humans. Biological Mass Spectrometry, 20, 247-252.

Kendler, K. S., Neale, M. C., Sullivan, P., Corey, L. A., Gardner, C. O., \& Prescott, C. A. (1999). A population-based twin study in women of smoking initiation 
and nicotine dependence. Psychological Medicine, 29, 299-308.

Lampe, J. W., \& Peterson, S. (2002). Brassica, biotransformation and cancer risk: Genetic polymorphisms alter the preventive effects of cruciferous vegetables. Journal of Nutrition, 132, 2991-2994.

Lessov, C. N., Martin, N. G., Statham, D. J., Todorov, A. A., Slutske, W. S., Bucholz, K. K., Heath, A. C., \& Madden, P. A. F. (2004). Defining nicotine dependence for genetic research: Evidence from Australian twins. Psychological Medicine, 34, 865-879.

Li, M. D., Cheng, R., Ma, J. Z., \& Swan, G. E. (2003). A meta-analysis of estimated genetic and environmental effects on smoking behavior in male and female adult twins. Addiction, 98, 23-31.

Lykken, D. T., McGue, M., \& Tellegen, A. (1987). Recruitment bias in twin research: The rule of twothirds reconsidered. Behavior Genetics, 17, 343-62.

McGue, M., Elkins, I., \& Iacono, W. G. (2000). Genetic and environmental influences on adolescent substance use and abuse. American Journal of Medical Genetics, 96, 671-677.

Messina, E. S., Tyndale, R. F., \& Sellers, E. M. (1997). Major role for CYP2A6 in nicotine C-oxidation by human liver microsomes. Journal of Pharmacology and Experimental Therapeutics, 282, 1608-1614.

Nakajima, M., Tanaka, E., Kwon, J-T., \& Yokoi, T. (2002). Characterization of nicotine and cotinine $\mathrm{N}$-glucuronidations in human liver microsomes. Drug Metabolism and Disposition, 30, 1484-1490.

Nakajima, M., Yamamoto, T., Nunoya, K., Yokoi, T., Nagashima, K., Inoue, K., Funae, Y., Shimada, N., Kamataki, T., \& Kuroiwa, Y. (1996). Role of human cytochrome P4502A6 in C-oxidation of nicotine. Drug Metabolism and Disposition, 24, 1212-1217.

O’Loughlin, J., Paradis, G., Kim, W., DiFranza, J., Meshefedjian, G., McMillan-Davey, E., Wong, S., Hanley, J., \& Tyndale, R. F. (2004, February). Genetically decreased CYP2A6 and the risk of tobacco dependence: A prospective study of novice smokers. Paper presented at the annual meeting of the Society for Research on Nicotine and Tobacco, Phoenix, AZ.

Oscarson, M., McLellan, R. A., Asp, V., Ledesma, M., Ruiz, M. L., Sinues, B., Rautio, A., \& IngelmanSundberg, M. (2002). Characterization of a novel CYP2A7/CYP2A6 hybrid allele (CYP2A6*12) that causes reduced CYP2A6 activity. Human Mutation, 20, 275-283.

Oscarson, M., McLellan, R. A., Gullsten, H., Yue, Q. Y., Lang, M. A., Bernal, M. L., Sinues, B., Hirvonen, A., Raunio, H., Pelkonen, O., \& Ingelman-Sundberg, M. (1999). Characterization and PCR-based detection of a CYP2A6 gene deletion found at a high frequency in a Chinese population. FEBS Letter, 448, 105-110.

Pam, A., Kemker, S. S., Ross, C. A., \& Golden, R. (1996). The 'equal environments assumption' in
MZ-DZ twin comparisons: An untenable premise of psychiatric genetics? Acta Geneticae Medicae et Gemellologiae (Roma), 45, 349-360.

Perez-Stable, E. J., Herrera, B., Jacob, P., III, \& Benowitz, N. L. (1998). Nicotine metabolism and intake in black and white smokers. Journal of the American Medical Association, 280, 152-156.

Pianezza, M. L., Sellers, E. M., \& Tyndale, R. F. (1998). Nicotine metabolism defect reduces smoking. Nature, 393,750 .

Pierce, J. P., Gilpin, E. A., Emery, S. L., Farkas, A. J., Zhu, S. H., Choi, W. S., Berry, C. C., Distefan, J. M., White, M. M., Soroko, S., \& Navarro, A. (1998). Tobacco control in California: Who's winning the war? An evaluation of the Tobacco Control Program 1989-1996. Retrieved April 16, 2004, from http://ssdc.ucsd.edu/tobacco/reports

Pomerleau, O. F., Collins, A. C., Shiffman, S., \& Pomerleau, C. S. (1993). Why some people smoke and others do not: New perspectives. Journal of Consulting and Clinical Psychology, 61, 723-731.

Pomerleau, C. S., Garcia, A. W., Pomerleau, O. F., \& Camerson, O. G. (1992). The effects of menstrual phase and nicotine withdrawal on nicotine intake and on biochemical and subjective measures in women smokers: A preliminary report. Psychoneuroendocrinology, 17, 627-638.

Rao, Y., Hoffmann, E., Zia, M., Bodin, L., Zeman, M., Sellers, E. M., \& Tyndale, R. F. (2000). Duplications and defects in the CYP2A6 gene: Identification, genotyping, and in vivo effects on smoking. Molecular Pharmacology, 58, 747-755.

Schoedel, K. A., Hoffmann, E. B., Xu, B., Rao, Y., Sellers, E. M., \& Tyndale, R. F. (2004, February). CYP2A6 genetically slow nicotine inactivators smoke fewer cigarettes per day and have a lower risk for smoking. Paper presented at the annual meeting of the Society for Research on Nicotine and Tobacco, Phoenix, AZ.

Schulz, T. G., Ruhnau, P., \& Hallier, E. (2001). Lack of correlation between CYP2A6 genotype and smoking habits. Advances in Experimental Medicine and Biology, 500, 213-215.

Sellers, E. M., Kaplan, H. L., \& Tyndale, R. F. (2000). Inhibition of cytochrome P450 2A6 increases nicotine's oral bioavailability and decreases smoking. Clinical Pharmacology and Therapeutics, 68, 35-43.

Seto, B. (2001). History of medical ethics and perspectives on disparities in minority recruitment and involvement in health research. American Journal of Medical Sciences, 322, 248-252.

StataCorp. (2001). Stata statistical software (Release 7.0) [Computer software]. College Station, TX: Stata Corporation.

Stolerman, I. P., \& Jarvis, M. J. (1995). The scientific case that nicotine is addictive. Psychopharmacology, 117, 2-10. 
Sullivan, P. F., \& Kendler, K. S. (1999). The genetic epidemiology of smoking. Nicotine \& Tobacco Research, 1(Suppl. 2), S51-S57.

Swan, G. E., Benowitz, N., Carmelli, D., Jacob, P., III, \& Karan, L. (2001). Pharmacokinetics of nicotine in twins [Abstract]. Nicotine \& Tobacco Research, 3(3), 278.

Swan, G. E., \& Carmelli, D. (1997). Behavior genetic investigations of cigarette smoking and related issues. In E. P. Noble \& K. Blum (Eds.), Handbook of psychiatric genetics (pp. 379-398). Boca Raton, FL: CRC Press.

Swan, G. E., Hudmon, K. S., \& Khroyan, T. V. (2003). Tobacco dependence. In A. Nezu \& C. Nezu (Eds.), Health Psychology (pp. 147-168). New York: Wiley.

Swan, G. E., Jack, L. M., \& Ward, M. M. (1997). Subgroups of smokers with different success rates after use of transdermal nicotine. Addiction, 92, 207-218.

True, W. R., Xian, H., Scherrer, J. F., Madden, P. A., Bucholz, K. K., Heath, A. C., Eisen, S. A., Lyons, M. J., Goldberg, J., \& Tsuang, M. (1999). Common genetic vulnerability for nicotine and alcohol dependence in men. Archives of General Psychiatry, 56, 655-661.

Tyndale, R. F., \& Sellers, E. M. (2001). Variable CYP2A6-mediated nicotine metabolism alters smoking behavior and risk. Drug Metabolism and Disposition, 29(4 Pt 2), 548-552.

U.S. Census Bureau. (2004). United States Census 2000 data, 2000 [Data file]. Retrieved from http://factfinder. census.gov

van den Oord, E. J. C. G., MacGregor, A. J., Sneider, H., \& Spector, T. D. (2004). Modeling with measured genotypes: Effects of the vitamin D receptor gene, age, and latent genetic and environmental factors on bone mineral density. Behavior Genetics, 34, 197-206.

van den Oord, E. J. C. G., \& Sneider, H. (2002). Including measured genotypes in statistical models to study the interplay of multiple factors affecting complex traits. Behavior Genetics, 32, 1-22.
Vesell, E. S., Page, J. G., \& Passanti, T. G. (1971). Genetic and environmental factors affecting ethanol metabolism in man. Clinical Pharmacology and Therapeutics, 12, 192-201.

Weber, J. L., \& May, P. E. (1989). Abundant class of human polymorphisms which can be typed using the polymerase chain reaction. American Journal of Human Genetics, 44, 338-396.

Weber, W. W. (1997). Pharmacogenetics. New York: Oxford University Press.

Xu, C., Goodz, S., Sellers, E. M., \& Tyndale, R. F. (2002). CYP2A6 genetic variation and potential consequences. Advances in Drug Delivery Reviews, 54, 1245-1256.

Xu, C., Rao, Y. S., Xu, B., Hoffman, E., Jones, J., Sellers, E. M., \& Tyndale, R. F. (2002). An in vivo pilot study characterizing the new CYP $2 A 6 * 7, * 8$, and $* 10$ alleles. Biochemical and Biophysical Research Communications, 290, 318-324.

Yamazaki, H., Inoue, K., Hashimoto, M., \& Shimada, T. (1999). Roles of CYP2A6 and CYP2B6 in nicotine Coxidation by human liver microsomes. Archives of Toxicology, 73, 65-70.

Yang, H., Li, X., Cao, W., Lu, J., Wang, T., Zhan, S., Hu, Y., \& Li, L. (2002). Chinese National Twin Registry as a resource for genetic epidemiologic studies of common and complex diseases in China. Twin Research, 5, 347-351.

Zhang, X., Amemo, K., Ameno, S., Iwahashi, K., Kinoshita, H., Kubota, T., Mostofa, J., \& Ijiri, I. (2001). Lack of association between smoking and CYP2A6 gene polymorphisms in a Japanese population. Nihon Arukoru Yakubutsu Igakkai Zasshi, 36, 486-490.

Zhou, S., Koh, H. L., Gao, Y., Gong, Z. Y., \& Lee, E. J. (2004). Herbal bioactivation: The good, the bad and the ugly. Life Sciences, 74, 935-968. 